\title{
O TRABALHO INFORMAL DE RUA RECONFIGURADO: sua função como agente da acumulação ${ }^{1}$
}

\author{
Bruno José Rodrigues Durães*
}

\begin{abstract}
O presente artigo aborda os trabalhadores que ofertam produtos tecnológicos (celular, games, pen drivers etc.) no espaço conhecido como Camelódromo do Feiraguai, situado na cidade de Feira de Santana, Bahia, Brasil. Pretendeu-se responder às seguintes questões: o que chamamos aqui de camelô (ou vendedor ambulante) de tecnologia, será uma forma diferenciada da relação de trabalho informal, realizado nas ruas, onde a lógica predominante é a do negócio (do lucro), correspondente à empresa, e não a lógica do trabalho (ligado à sobrevivência)? trata-se de atividades que agora passam a servir como veias de expansão do capital? Para responder às perguntas tivemos como objetivo geral, explorar essa nova diferenciação que se encontra presente nas formas de trabalho de rua existentes na sociedade brasileira atual, buscando compreendê-la como uma nova (re) configuração. Consideramos que esse fenômeno evidencia um tipo de atividade que sofre interferências diretas do mundo formal, reconfigurando-se e assumindo feições empresariais. Para a realização da pesquisa, foram aplicados 151 questionários, que permitiram constatar que se trata de um trabalho de estilo e lógica empresarial, mas ainda realizado nos marcos do trabalho informal.
\end{abstract}

PALAVRAS-CHAVE: Informalidade. Camelô de tecnologia. Capitalismo.

\section{INTRODUÇÃO}

O capitalismo historicamente assumiu formatos diversos alternando a exploração daqueles que vivem do trabalho, por vezes, como algo que ficava oculto na aparência dos fenômenos, ou na periferia do mundo, outras vezes disfarçada de legalidade e, em outros momentos como algo inegável, que fica evidente no momento atual com o trabalho de entregadores/as por aplicativos. Nessa perspectiva, a dialética entre capital e trabalho vem sendo ressignificada ao longo do tempo, embora sempre estivesse presente ao por em cena o processo de precarização do trabalho. A relação de assalariamento também veio se metamorfoseando, chegando, em alguns casos, a mesclar-se o trabalho autônomo (conta própria), com uma feição formal,

\footnotetext{
* Universidade Federal do Recôncavo da Bahia (UFRB). Centro de Artes, Humanidades e Letras.

Rua Ana Nery, 25, Centro. Cep: 44300-000. Cachoeira Bahia - Brasil.bruno@ufrb.edu.br https://orcid.org/0000-0002-7571-0918

${ }^{1} \mathrm{O}$ presente artigo é resultado de um Projeto de Pesquisa denominado "Camelôs globais ou de tecnologia: tradição, resistência e modernização a serviço do capital", que contou com o apoio do CNPq através do Edital Universal de pesquisa de 2013.
}

como no caso de catadores de recicláveis que se encontram nas ruas das cidades brasileiras, e que terminam vendendo para cooperativas ou empresas atravessadoras. Por vezes, possuem alguma forma de vínculo de trabalho, ainda que sem carteira assinada, recebendo por peça de produto catado (Gama, 2015). Existe também a situação da mescla de atividades informais e/ ou ilegais dentro de empresas formais, caracterizando um processo de informalização do formal (Tavares, 2004), ${ }^{2}$ e temos ainda uma gama de trabalhadores por aplicativos que atuam em diferentes parte do mundo (entregadores/as) e vivem uma espécie de relação salarial disfarçada entre "parceiros" (Abílio, 2017).

Cabe também destacar o enorme volume de trabalhadores/as informais existentes no mundo. O trabalho informal representa

${ }^{2}$ Hoje temos uma formalização do informal via leis que tentam legalizar a prática informal, mas ainda sendo informal ou em situação tão incerta e adversa como, um exemplo é o trabalho intermitente na dita reforma trabalhista de 2017 ou nas tentativas governamentais do Brasil em 2020, que estão propondo contratos sem direitos. A nova lei do trabalho (Lei 13467/2017) apresenta a figura do trabalho autônomo, intermitente e o dito home office, que mais parecem formas de trabalho informais agora reguladas pelo Estado. Ou seja, a lei passa a assumir a legalidade da contratação de autônomo diretamente por empresa, a redução de salário, de direitos. Ver sobre esse debate em Belluzzo (2020) e Druck; Jesus; Dutra (2019). 
cerca de 2 bilhões de pessoas, ou 6 a cada 10 pessoas ocupadas a depender do país, ou ainda $60 \%$ do total de trabalhadores, conforme a Organização Internacional do Trabalho-OIT. Em 2020, dentro do contexto da Pandemia por Covid-19 (coronavírus), restou, muitas vezes, o dilema do contágio (nas ruas) ou morrer de forme (ILO, 2020), pois, muitos trabalhadores informais precisam do trabalho imediato, cotidiano, para sobrevivência.

Portanto, esse quadrante histórico atual é marcado pela expansão do trabalho informal, o que revela as contradições do próprio capitalismo, pois demonstra que a não existência de direitos sociais passa a ser corrente, revelando também que o capitalismo não consegue garantir uma vida digna e um trabalho decente mesmo após tantas descobertas tecnológicas, além de demonstrar como se difunde uma ideia de positividade, de sucesso e de liberdade dentro do denominado empreendedorismo, embora na verdade, seja a aparência do fenômeno, que esconde contradições, as quais ficaram em evidência na Pandemia (Antunes, 2020).

Dentro desse cenário de alterações do sistema capitalista é que se insere a proposta do presente artigo. Nosso objetivo é analisar a reconfiguração do trabalho informal de rua, no caso do que chamamos de camelôs de tecnologia, buscando entender a sua relação com o processo de acumulação do capital, e sua existência em uma cidade do interior da ชิ região Nordeste do Brasil, objetivando revelar ๙ como as transformações do capitalismo não ठे se limitam às capitais, e nem a determinada ชิ região específica do país. Como afirma Druck Ji (2013) sobre esse processo mais geral de domi¿. nação do sistema capitalista e da imposição da ळ condição social precária como forma corrente ثे e permanente de existência laboral:

[A] Precarização Social do Trabalho é um processo econômico, social e político que se tornou hegemônico e central na atual dinâmica do novo padrão de desenvolvimento capitalista - a acumulação flexível - no contexto de mundialização do capital e das políticas de cunho neoliberal. Trata-se de uma estratégia patronal, em geral apoiada pelo Estado e seus governos, que tem sido implementada em todo o mundo, cujos resultados práticos se diferenciam muito mais por conta da história passada de cada país, refletindo os níveis de democracia e de conquistas dos trabalhadores, do que da história presente, cujos traços principais os aproximam e os tornam semelhantes, pois a precarização social do trabalho se impõe como regra e como estratégia de dominação [...] (Druck, 2013, p.373-374).

\section{A RECONFIGURAÇÃO DA INFOR- MALIDADE DE RUA}

Nessa via, o capitalismo passou por transformações, mas manteve seu processo de dominação. Aconteceram mudanças, adotando modelos diversos de organização do trabalho (fordismo, taylorismo, toyotismo), mas as lógicas da dominação e do lucro sempre estiveram presentes. Harvey (1999) classifica esse processo, presente no capitalismo de finais do século XX, e que pode ser estendido para a atualidade, no início do século XXI (dentro da denominada indústria 4.0), como a fase de acumulação flexível, na qual passa a existir uma mudança profunda na própria noção de tempo e de espaço, o que termina contribuindo para ampliação do processo de exploração. Harvey (2005; 2020) caracteriza o capitalismo adicionalmente como a recolocação de formas de exploração absoluta do trabalho, a exemplo da super-exploração, como sendo a nova face do imperialismo hoje, na qual o capital se expande no espectro da globalização em busca de novos nichos de trabalho barato (incluindo o trabalho digital e por aplicativos) dentro do "capitalismo de plataforma” (Srnicek, 2016; Grohmann, 2020) e de vigilância (Zuboff, 2018).

Essa nova configuração do mundo do trabalho advinda destes processos mais gerais de mudanças da forma societal de organização do capital (Mészáros, 2002) comporta, segundo Antunes (2005), uma classe trabalhadora ampliada, não mais restrita ao trabalho fabril. Continua o autor na sua definição da classe trabalhadora: 
[...] hoje a classe-que-vive-do-trabalho, deve incorporar também aqueles que vendem sua força de trabalho, em troca de salário, como o enorme leque de trabalhadores precarizados, terceirizados, fabris e de serviços, part-time, que se caracterizam pelo vínculo de trabalho temporário, pelo trabalho precarizado, em expansão na totalidade do mundo produtivo (Antunes, 2005, p. 52).

Nesse início do século XXI, o mercado de trabalho incorpora crescentemente trabalhadores não considerados produtivos, como no caso de determinados serviços e atividades informais que não geram valor diretamente. ${ }^{3}$ Contudo, a marca do assalariamento (separação capital e trabalho, via pagamento de um salário, não necessariamente com carteira de trabalho assinada) apresenta-se como fio condutor dessa nova morfologia, assim como a marca da exploração e do capital contra o trabalho (Antunes, 2000, 2020). É através do trabalho assalariado (precário, informal, cooperado, terceirizado etc.) que se amplia o contingente de trabalhadores na atualidade como trabalhadores por aplicativos/uberizados (Abílio, 2017, 2020; Aliança Bike, 2020; Abílio et.al, 2020) etc. ${ }^{4}$ E por estes meios, o capitalismo reinventa formas de expansão do lucro e da formação de uma massa excedente de trabalhadores, em plena atividade, aptos a buscar a sobrevivência, sujeitando-se às mais aviltantes formas de trabalho. Como exemplos destas formas contemporâneas de exploração, têm-se:

${ }^{3}$ Ser produtivo é ser parte constitutiva do processo de formação do valor, parte do quantum de trabalho social médio necessário para produzir uma mercadoria, o tempo de trabalho corporificado usado na producão de uma coisa útil (coisa tangível ou intangível, material ou imaterial). Sobre isso, ver Marx (2002), Capital, Livro 1, Capítulo 1, A Mercadoria. Existe também o valor no campo de serviços também, que é entendido como produtivo e que o serviço é tido como uma mercadoria, assim como existe o valor trabalho em geral que é produzido por toda forma de trabalho, não iremos aprofundar isso aqui, mas a noção de "valor" precisa ser compreendida com as mudanças tecnológicas e societais.

${ }^{4}$ Ocorre ampliação também através do trabalho por demanda, que hoje se denomina de "uberização" (Boudaud,2015) ou das formas de "uberizar" a economia (Carney, 2014) ou a dita economia Uber (Hill, 2015). Essas novas formas de trabalho também são caracterizadas dentro da denominada Economia do Compartilhamento (Shared Economy), que revelam, na verdade, formas de exploração com longas jornadas e busca incessante pelo lucro (Schor, 2014; Scholz, 2016; De Stefano, 2016; Slee, 2017; Antunes, 2018) e de trabalho assalariado disfarçado de autônomo. diversas empresas de terceirização, inclusive, situadas no serviço público, nas próprias Universidades, funcionando, muitas vezes, como empresas de fachada, que abusam do trabalhador, por vezes sem conceder os benefícios trabalhistas (Souza, 2012; Santana; Druck, 2015; Gimenez; Klein, 2016; Campos, 2018). Conforme Druck et al. (2018), a terceirização no setor público ocorre em diferentes frentes:

[...] há uma grande diversidade de formas de terceirização na esfera pública, como as concessões, as parcerias público-privadas, as cooperativas, as organizações não governamentais (ONGs), as organizações da sociedade civil de interesse público (Oscips), as organizações sociais (OSs) e a contratação de empresas prestadoras de serviços (ou intermediadoras de mão de obra) (Druck et. al., 2018, p.133).

E concluem afirmando que "[...] a terceirização no serviço público é um dos mecanismos mais importantes e eficientes de desmonte do conteúdo social do Estado e de sua privatização" (Ibid., p.135). Desse modo, as formas de trabalho terceirizadas: promovem verdadeiras rupturas na vida dos envolvidos (objetivamente e subjetivamente), consolidando uma existência imprevisível, aqui pensando nas reflexões postas por Richard Sennett no livro "Corrosão do Caráter" (2000); e rompem com uma possível unidade na classe trabalhadora, pois, colocam algumas pessoas nas mesmas funções para exercerem atividades similares, em condições e salários diferenciados, identidades fragmentadas e laços frágeis (Godinho, 2008). Isto pode provocar disputas internas no próprio processo de trabalho.

Ademais, existe uma gama de latifundiários que contrata trabalhadores rurais sem pagamento de garantias trabalhistas, e geralmente, sem pagar salário mínimo, compondo, assim, um regime de escravidão moderna. Por fim, existem as pequenas fábricas que usam trabalhadores imigrantes nordestinos ou estrangeiros em São Paulo, em regimes exaustivos de trabalho, morando no próprio local de trabalho, desrespeitando as leis, e compondo pequenos empreendimentos informais. Exis- 
tem ainda inúmeras formas de assalariamento ilegal, informais, incluídas no universo formal de trabalho das empresas, que subcontratam trabalhadores para realização de parte do processo produtivo, como no caso de indústrias de confecção. A este respeito, os trabalhadores/as em pequenas fábricas de confecção no Paraná, ver Ângela Lima (2009). Ainda podemos nos referir aos trabalhos em cooperativas, associações de catadores, reciclagem, e outros.

Nesse sentido, pode-se considerar que determinados trabalhadores não participam diretamente da composição clássica do "valor", todavia, sua inserção na produção da riqueza social não deixa de ocorrer (bem como na geração de valor-trabalho em geral). Não vemos como deixá-los de lado no circuito do capital, já que eles também são úteis ao sistema, ainda que atuem na área comercial, como no caso de determinados informais que contribuem para completar o ciclo do capital. Voltaremos a tal questão à frente.

Expandindo um pouco mais essa caracterização, poderemos também incluir os trabalhadores de rua nesse alargamento da concepção de classe trabalhadora, ou na nova morfologia do trabalho, considerando-se que sempre estiveram presentes como participantes do trabalho urbano, constituindo peça chave em determinados momentos de fluxos comerciais das cidades, principalmente, diante da predominância do capitalismo comercial durante $o$ período da metrópole-colônia. A respeito do จิ período do capitalismo comercial brasileiro, ver Caio Prado Jr (1994), Fernandes (1976) e Novais (1995). Quanto aos trabalhadores de rua de meados do século XIX, ver Reis (1991, 2000, 2019) e Durães (2006, 2012). Na verda$\therefore$ de, o capitalismo brasileiro, e de muitos países ळ da América Latina, tiveram como característi$\Rightarrow$ ca este traço de incorporar formas diferenciadas de trabalho, todas participando de algum modo do processo de acumulação capitalista.

No momento atual, desde o último quartel do século XX, o trabalho de rua passa a ter um peso mais significativo nas relações propriamente produtivas do sistema capitalista. Só a partir das décadas de 70, 80 e 90, as atividades informais, principalmente exercidas nas ruas, passaram a servir como elementos de expansão do valor. De fato, não o produzem diretamente em alguns casos, mas contribuem para sua realização enquanto "trabalhadores gratuitos" (Durães, 2005, p.233). Dentro desse cenário, vive-se uma expansão de formas de trabalho desregulamentadas, socialmente desprotegidas, que tem na informalidade de rua sua forma mais visível. As relações informais ganham, assim, notoriedade, rompendo com certas concepções de que o avanço do capitalismo iria reduzir a sua participação nas economias. O que se vê é um aumento crescente do contingente destes trabalhadores na composição do mercado de trabalho em países de distintas regióes do globo. ${ }^{5}$ Portanto, estudar a informalidade no presente é estudar um fenômeno mundial, no sentido de que começam a surgir formas de trabalho desregulamentadas (sem registro) nos países centrais, compondo parte dos denominados trabalhos atípicos (Vasapollo, 2005). ${ }^{6}$ Além disso, existem outras denominações para estas formas de trabalho que não passam pela conceituação da informalidade (trabalho degradante, etc.). No momento, não nos deteremos em tal problemática, ainda que a reconheçamos como relevante. Vale citar a preocupação de Lautier (2004, p.110), que questiona se essas atividades informais não serão o futuro dos países "desenvolvidos". Hoje vemos que o capitalismo tenta colocar essas atividades como modelos para constituir uma sociedade sem direitos, seguindo uma lógica de servidão digital (Antunes, 2018).

O fenômeno da informalidade no Brasil (e no mundo) atualmente já ultrapassa a mera fronteira das ruas. A informalidade é global, ${ }^{7}$

${ }^{5}$ Os dados do IBGE/PNAD para o caso brasileiro, nos últimos anos, evidenciam a composição relevante da informalidade sempre próxima de 50\% da População Economicamente Ativa. Ver sítio www.ibge.gov.br. Em 2020, temos cerca de 40 milhões de trabalhadores informais no Brasil.

${ }^{6}$ Sobre trabalho informal em outros países ver: Lautier (2004), Vasapollo (2005), Silva (2010), Mosca (2010), Chen (2012), Bauwens; Lemaître (2014), William; Shahid; Martíne (2016), ILO (2013, 2018), Bromley; Wilson (2018), Canclini (2019), e Banks; Lombard; Mitlin (2020).

${ }^{7}$ Sendo também informacional, virtual/internet e incorpo- 
seja composta por imigrantes (em países centrais), seja por populações que já passaram por emprego estável/formal. ${ }^{8}$ Há uma parcela de empresas e até de indústrias espalhadas pelo mundo que utilizam trabalhadores subcontratados (via aplicativos), seja com contratação direta ou através de redes de terceirizações, objetivando mascarar práticas perversas de informalidade para baratear seus custos.

\section{OS CAMELÔS DE TECNOLOGIA}

Assim, a proposta do presente artigo é apresentar algumas transformações do trabalho de rua, tendo como exemplo uma pesquisa empírica realizada em Feira de Santana, segunda maior cidade em termos populacionais do estado da Bahia (após Salvador), possuindo uma população estimada de 619.609 mil habitantes em 2020 (IBGE, 2020). A pesquisa foi realizada no espaço conhecido como Camelódromo Feiraguai (no período de 2014-2016), o qual surgiu ${ }^{9}$ a partir de uma antiga feira popular em 1980, mas somente em 1996 os comerciantes vão para a praça onde estão hoje e ganham um formato de camelódromo nessa época (Oliveira, 2013). Santos descreve assim o surgimento do Camelódromo:

[...] foi criado em 1980, a partir da chamada "Feira do Rolo" e posteriormente, um camelódromo que ficou assim conhecido devido às vendas de mercadorias provenientes do circuito China - Paraguai e Brasil. [...] foi realocado pelo poder Municipal do Calçadão da Sales Barbosa, em 1996, para a Praça Presidente

ra também o trabalho imaterial/intelectual e digital.

${ }^{8}$ A informalização dos formais já vem ocorrendo no Brasil e na América Latina. Certos trabalhadores formais hoje só encontram nas atividades informais, principalmente as de rua, com seus conjuntos de normas e procedimentos ditos ilegais, os meios e formas de reproduzirem-se socialmente. Sobre a reflexão conceitual em torno da entrada de ex-trabalhadores formais no universo informal, o que denomina-se de "nova informalidade", ver: (Cacciamali, 2000, Filgueiras; Druck; Amaral, 2000; Lima e Soares, 2002; Machado Da Silva, 2002).

${ }^{9} \mathrm{O}$ Feiraguai é considerado um dos maiores camelódromos em movimentação de produtos e de dinheiro do país (produtos originais e pirateados, assim como produtos que entram sem nota fiscal no Brasil). E considerado também um ponto turístico da cidade (Campos, 2013). Sobre o comércio informal em Feira de Santana ver Teles (2017).
Médici, às margens da Avenida Monsenhor Mário Pessoa, prolongamento da av. Presidente Dutra que interliga as BR 324 e 116-Sul (Santos, 2016, p.79).

Este autor informa que contabilizou " 360 comerciantes” neste local, apesar da Associação de Camelôs local ter informado que o total era de 560 boxes em 2014. ${ }^{10}$ Durante a pesquisa, estivemos no local em momentos diferentes (entre 2014 e 2016) e contabilizamos número similar ao citado por Santos (2016) o que sugere a existência de grande rotatividade - fechar um ponto um dia e abrir em outro - bem como, alguns camelôs que possuem mais de um ponto e junta um no outro. Logo, seguiremos também o número total de 360 comerciantes, mas focando apenas no pessoal que trabalha com produtos eletrônicos, contabilizamos em 151, conforme contagem própria, o que representa cerca de $42 \%$ de todo o Camelódromo. Entrevistamos 151 trabalhadores/as (sendo 54 camelôs proprietários e 97 camelôs funcionários ${ }^{11}$ ) em $2015^{12}$ e torna-se evidente como o trabalho informal se reconfigura e passa a atender ainda mais a lógica de acumulação do capital. ${ }^{13}$

${ }^{10}$ Tem reportagem que fala em 615 boxes (Maia,2019). Importante dizer que um boxe chega a ser vendido por $70 \mathrm{mil}$ reais, ver: https://ba.mgfimoveis.com.br/venda-ba-feira-santana-box-no-feiraguai-hildebrando-imoveis-vende-se-box-no-45011549. O valor do aluguel chega a 6 mil reais por mês e cada dono de boxe paga cerca de 60 reais mensais para associação dos camelôs do camelódromo (Santos, 2016).

${ }^{11}$ Os entrevistados foram escolhidos de forma aleatória. Fomos seguindo todos os boxes. Como é uma atividade que envolve também produtos ilegais e/ou sem nota-fiscal, logo, às vezes a pessoa se recusava participar. Mas tivemos poucas recusas, pois fomos a campo com apoio da Associação do Camelódromo. Todavia, não tivemos como controlar a quantidade de proprietárias e funcionários, íamos aceitando as entrevistas da forma como iam surgindo. Entretanto, entrevistamos apenas os camelôs de produtos tecnológicos.

${ }^{12}$ Apesar da pesquisa ter sido focada mais na questão qualitativa de informacões (com várias perguntas abertas no questionário e também com observação e elaboração de diário de campo), conseguimos aplicar questionário praticamente com todas as "lojas" de camelôs de tecnologia do camelódromo na época. Assim, fizemos um censo dos trabalhadores e foi possível, dessa forma, obter uma resposta mais fidedigna com a realidade do trabalho desse tipo de camelô. Em geral, consideramos o camelô de tecnologia como o dono e o funcionário, apesar das diferenças internas, mas estão em uma condição de classificação similar como trabalhadores de rua.

${ }^{13}$ Fizemos uma pesquisa similar no doutorado em Ciências Sociais na Unicamp, em que pudemos pesquisar os camelôs de tecnologia (com 42 entrevistas) no Camelódromo da Uruguaiana em 2010, Centro do Rio de Janeiro. Agora foi possível realizar uma pesquisa com mais profundidade e abrangência, assim, podendo validar ou contestar achados anteriores. No geral, a informalidade de rua não representa 
O trabalho informal é multifacetado, apresenta-se como uma forma de trabalho similar, que pode ser tão rentável e precário quanto o trabalho formal assalariado. Na verdade, a informalidade (sobretudo aquela exercida nas ruas) sempre foi concebida como o lado precário e não produtivo sempre colocado como o refúgio daqueles/as que não conseguiram outro trabalho. Essa é uma dimensão já bastante difundida, contudo, no presente momento da sociedade, emerge um tipo de trabalho de rua que se mostra singular, como fruto da própria metamorfose da organização capitalista. Trata-se dos camelôs globais ou de tecnologia (Durães, 2013). Embora o trabalho informal ganhe outros sentidos, como dentro de empresas formais, prestando serviços, ou mesmo como empresa principal, tem como característica geral a contratação ilegal de trabalhadores com redução de direitos.

Como se sabe, a informalidade na sociedade brasileira é uma constante, não apenas em formas de trabalho de rua, mas também, como uma forma de baratear os custos, precarizando determinados postos de trabalho antes estáveis. Apesar de representar também um elemento cultural no Brasil, tem sido usada como artifício para burlar as leis - espaço de sobrevivência para milhões de pessoas. Todavia, ela deixa de ser uma forma de trabalho com características exclusivas, tida como um trabalho pretérito, passando a um trabalho tipicamente capitalista. Não se pode mais conceber a informalidade จิ como algo apartado do capitalismo, nem como N resquício de formas passadas de trabalho. Ao ฮิ contrário, a informalidade se reconfigura. Ela é \& marcada pela redução de direitos, benefícios e Ii rendas, apesar da camuflagem de formalidade, $\overrightarrow{2}$ que ocorre em certos casos, e da conquista da ले autonomia. Por certo, a fronteira entre trabalho formal e informal, no aspecto conceitual, caiu por terra, e o registro em carteira de trabalho não é mais um atributo eficaz para distingui-los.

No caso da informalidade de rua, esse processo de reconfiguração ficou bastante evi-

apenas a vida no limite da sobrevivência, mas um negócio - “empresarização” da rua (Durães, 2013). dente, basta observar o estilo de determinados Camelódromos no Brasil, que ganham a aparência de lojas, mas quase sempre sem emitir nota fiscal, nem dar garantias, mas contratando funcionários, aceitando cartões.

\section{O Perfil dos camelôs de produtos tecnoló- gicos de Feira de Santana}

Considerando-se o total de entrevistados (151), cerca de 60\% são homens, conforme tabela 01 abaixo, indicando que a participação masculina no Feiraguai é predominante. ${ }^{14} \mathrm{Em}$ relação à escolaridade, nota-se uma expressiva formação escolar, 53\% dos entrevistados possuem o segundo grau e $16 \%$ possuem nível superior ou estão cursando (ver tabela 02 abaixo). Estes dados indicam que os trabalhadores de rua apresentam um nível relevante de escolaridade, mas continuam migrando para o mercado informal, sugerindo que divergem dos trabalhadores de rua "tradicionais" (Durães, 2013) os quais, em geral, têm baixa escolaridade e sem qualificação formal.

Tabela 01 - Entrevistados/as por Sexo

\begin{tabular}{l|c|c}
\hline Sexo & Frequência & \% \\
\hline Masculino & 86 & 57,0 \\
\hline Feminino & 65 & 43,0 \\
\hline Total & 151 & 100,0 \\
\hline Fonte: Pesquisa direta, 2015.
\end{tabular}

Tabela 02 - Entrevistados/as por Escolaridade

\begin{tabular}{l|c|c}
\hline Escolaridade & Frequência & \% \\
\hline $1^{\circ}$ grau incompleto & 20 & 13,2 \\
\hline $1^{\circ}$ grau completo & 5 & 3,3 \\
\hline $2^{\circ}$ grau incompleto & 21 & 13,9 \\
\hline $2^{\circ}$ grau completo & 80 & 53,0 \\
\hline Superior incompleto & 17 & 11,3 \\
\hline Sup. Completo & 5 & 3,3 \\
\hline Pós-graduação & 2 & 1,3 \\
\hline $\begin{array}{l}\text { Não sabe/não } \\
\text { respondeu }\end{array}$ & 1 & 0,7 \\
\hline Total & 151 & 100,0 \\
\hline
\end{tabular}

Fonte: Pesquisa direta, 2015

14 Isso também ficou demonstrado na pesquisa de Santos (2016), em que ele pesquisou 308 camelôs e cerca de $64,6 \%$ eram homens. 
Os dados relacionados à cor/raça dos pesquisados mostram uma quantidade marcante que se autodeclara negros (cerca de 87\%) sendo pardos (45\%) e pretos (42\%). Estes números mostram uma participação representativa de negros, conforme tabela 03.

Tabela 03 - Entrevistados/as por Cor

\begin{tabular}{l|c|c}
\hline Cor & Frequência & \% \\
\hline Preto & 64 & 42,4 \\
\hline Branco & 11 & 7,3 \\
\hline Amarelo & 6 & 4,0 \\
\hline Pardo & 68 & 45,0 \\
\hline Não sabe/não respondeu & 2 & 1,3 \\
\hline Total & 151 & 100,0 \\
\hline Fonte: Pesquisa direta, 2015 & &
\end{tabular}

Entre os entrevistados, temos $41 \%$ que fez algum curso profissionalizante, conforme tabela 04 e 05 abaixo, sendo que cerca de $40 \%$ já fizeram cursos de eletrônica e/ou informática, o que demonstra uma formação prévia na área de tecnologia.

Tabela 04 - Entrevistados/as se fez Curso Profissional

\begin{tabular}{l|c|c}
\hline Já fez algum curso? & Frequência & \% \\
\hline Sim & 61 & 41,2 \\
\hline Não & 86 & 58,1 \\
\hline Não sabe/não respondeu & 1 & 0,7 \\
\hline Total & 148 & 100,0 \\
\hline
\end{tabular}

Fonte: Pesquisa direta, 2015.

Tabela 05 - Entrevistados/as Por tipo de Curso

\begin{tabular}{l|c|c}
\hline Curso & Frequência & $\%$ \\
\hline $\begin{array}{l}\text { Telemarketing//secretariado/ } \\
\text { escritório/aux. Administrativo/ } \\
\text { logistica/emplilhador/contabilidade/ } \\
\text { estoque/faturamento }\end{array}$ & 11 & 17,5 \\
$\begin{array}{l}\text { Serviço geral/pedreiro/garçom/ } \\
\text { mecânico/frentista/torneiro } \\
\text { mecânico/operário/motorista/téc } \\
\text { saúde/assist téc/ outros téc. }\end{array}$ & 19 & 30,2 \\
$\begin{array}{l}\text { Eletrônica/manutenção de } \\
\text { celular/técnico em publicidade, } \\
\text { administração de empresas de nível } \\
\text { médio/informática }\end{array}$ & 25 & 39,7 \\
$\begin{array}{l}\text { Gestão de negócios/marketing/ } \\
\text { vendas/línguas/educador }\end{array}$ & 5 & 7,9 \\
\hline Não sabe/não respondeu & 3 & 4,8 \\
\hline Total & 63 & 100,0 \\
\hline Fonte: Pesquisa direta, 2015. & &
\end{tabular}

Entretanto, a maioria dos entrevistados recebe até dois salários mínimos $(\mathrm{SM})$, sendo que destes, 75 são funcionários e 05 proprietários, o que proporcionalmente significa que 89\% dos funcionários (que responderam à questão da renda) estão nessa faixa e apenas 10\% dos proprietários (ver tabela 06 abaixo). É importante ressaltar que os proprietários ganham mais do que os camelôs-funcionários, apesar de alguns não responderem a essa questão ou não expressarem o dado com fidedignidade, sobretudo, por se tratarem de ganhos mais elevados do que um salário mínimo. Ao se observar os dados sobre a renda, pode-se perceber que a partir de 3 SM não existem funcionários, o mesmo vai ocorrendo com o aumento dos rendimentos nas faixas seguintes, o que evidencia uma discrepância de rendimentos e abre espaço para se pensar como essa diferenciação de renda pode representar um elemento da dicotomia entre capital e trabalho. Portanto, existem proprietários com rendas a partir de $07 \mathrm{SM}$, ou seja, com uma renda alta para o universo do informal historicamente ligado ao limite da sobrevivência. Como disse um camelô-proprietário (em 2015) "Aqui, Graças a Deus, pode-se ganhar bem, consegue ter seu carro e também uma casa de praia, ou um sítio, estamos melhores do que várias profissões que existem por ai”. E em outro trecho da entrevista: "Aqui ganhamos mais que um professor da Federal, ganhamos mais que o senhor" ${ }^{15}$ Isso mostra outra característica em comum com o trabalho formal, que é a diferença expressiva de renda entre proprietário e funcionário. Além disso, alguns proprietários revelaram, posteriormente, que chegam a ganhar cerca de dez salários mínimos por mês.

${ }^{15}$ Entrevista realizada em 2015 no camelódromo do Feiraguai. Esse camelô foi entrevistado pelo pesquisador responsável - um professor com doutorado e dedicação exclusiva de Universidade Federal. 
Tabela 06 - Entrevistados/as por renda na atividade

\begin{tabular}{|c|c|c|c|c|c|c|c|c|c|}
\hline & \multicolumn{8}{|c|}{ REMUNERAÇÃO } & \multirow[b]{2}{*}{ Total } \\
\hline & até 1 S.M & 1 a 2 S.M & 2 a 3 S.M & $\begin{array}{c}3 \text { até } 4 \\
\text { S.M }\end{array}$ & $\begin{array}{c}4 \text { até } 5 \\
\text { S.M }\end{array}$ & $\begin{array}{c}5 \text { até } 7 \\
\text { S.M }\end{array}$ & $\begin{array}{c}7 \text { até } 10 \\
\text { S.M }\end{array}$ & $\begin{array}{c}\text { acima de } \\
10 \text { S.M }\end{array}$ & \\
\hline Proprietário & $\begin{array}{c}2 \\
(4 \%)^{*}\end{array}$ & $\begin{array}{c}3 \\
(6 \%) \\
\end{array}$ & $\begin{array}{c}8 \\
(16 \%) \\
\end{array}$ & $\begin{array}{c}3 \\
(6 \%) \\
\end{array}$ & $\begin{array}{c}4 \\
(8 \%) \\
\end{array}$ & $\begin{array}{c}15 \\
(30,6 \%) \\
\end{array}$ & $\begin{array}{c}9 \\
(18,3 \%) \\
\end{array}$ & $\begin{array}{c}5 \\
(10,2 \%) \\
\end{array}$ & 49 \\
\hline Funcionário & $\begin{array}{c}41 \\
(48,8 \%)^{* *} \\
\end{array}$ & $\begin{array}{c}34 \\
(40,5 \%) \\
\end{array}$ & $\begin{array}{c}8 \\
(9,5 \%) \\
\end{array}$ & $\begin{array}{c}1 \\
(1,2 \%) \\
\end{array}$ & 0 & 0 & 0 & 0 & 84 \\
\hline Total & 43 & 37 & 16 & 4 & 4 & 15 & 9 & 5 & $133^{* * *}$ \\
\hline
\end{tabular}

*Percentual em relação ao total de proprietário. ** Percentual em relação ao total de funcionários. *** 18 pesquisados/as não responderam a pergunta sobre renda Fonte: Pesquisa direta, 2015.

Ademais, cerca de $54 \%$ dos entrevistados indicam que este trabalho não é a sua única opção (ver tabela 07 abaixo), sugerindo duas tendências: a) não se trata mais de uma informalidade como último refúgio, mas como uma opção dentre outras; b) talvez passe a configurar um espaço efetivamente de sobrevivência mais qualificada e/ou um negócio.

Tabela 07 - Resposta a pergunta: Esse trabalho é a última opção?

\begin{tabular}{l|c|c}
\hline Última opção? & Frequência & \% \\
\hline Sim & 68 & 46,3 \\
\hline Não & 79 & 53,7 \\
\hline Total & $147^{*}$ & 100,0 \\
\hline
\end{tabular}

Fonte: Pesquisa direta, 2015;

* quatro pesquisados não responderam.

\section{O processo de formalização do trabalho de rua}

Os dados da tabela 08 (abaixo) indicam que cerca de $74 \%$ dos entrevistados realiza controle de vendas, o que corresponde a uma సิ característica típica do mercado formal. Ouขึ tras características empresariais que foram notadas na pesquisa como apresentamos a seguir $\underset{f}{*}$ de forma sintética: aproximadamente $57 \%$ do I total de entrevistados informou que faz esto$\dot{2}$ ques de mercadorias e alguns destes realizam $\stackrel{\infty}{>}$ empréstimos para compras (cerca de 8\%), enof quanto cerca de $61 \%$ (ou 92 pessoas) responderam que realizam vendas por cartão de crédito, bem como cerca de $45 \%$ dão garantia dos produtos comercializados, sugerindo que estes camelôs atuam como uma espécie de "loja" ambulante, nas ruas.
Tabela 08 - Entrevistados/as por controle de vendas

\begin{tabular}{l|c|c}
\hline Faz controle de vendas? & Frequência & $\%$ \\
\hline Sim & 111 & 73,5 \\
\hline Não & 38 & 25,2 \\
\hline Não sabe/não respondeu & $2^{*}$ & 1,3 \\
\hline Total & 151 & 100,0 \\
\hline
\end{tabular}

Fonte: Pesquisa direta, 2015.

*São funcionários que não souberam informar sobre controle de vendas.

Quase todos os camelôs confirmam a aparência de empresa (cerca de 91\% ou cerca de 137 pessoas). Percebemos que apesar de não possuírem registro, identificam-se como tal, o que se dá justamente por esse processo de formalização, além do fato de muitos estarem registrados como MEI - Micro Empreendedor Individual - uma lei do governo federal. Entretanto, não atuam como uma empresa tradicional, o que se atribui aos seguintes motivos: possuir uma estrutura similar a uma loja, aceitar cartões, ter salário fixo e benefícios (cerca de $45 \%$ dos pesquisados confirmaram), e terem CNPJ (via MEI), além do fato de pagarem impostos (cerca de 41,5\%, conforme tabela 09 abaixo). Ou seja, os entrevistados ressaltaram características de uma empresa formal.

Tabela 09 - Resposta a pergunta: Se parece com uma empresa?

\begin{tabular}{|c|c|c|}
\hline Se parece com uma empresa, por quê? & Frequência & $\%$ \\
\hline $\begin{array}{l}\text { Temos registo (CNPJ)/paga imposto/ } \\
\text { funciona como microempresa }\end{array}$ & 44 & 41,5 \\
\hline Temos estrutura de loja/empresa & 36 & 34,0 \\
\hline $\begin{array}{l}\text { Assinamos carteira/pagamos salário } \\
\text { fixo e benefícios }\end{array}$ & 13 & 12,3 \\
\hline $\begin{array}{l}\text { Temos regras, horários a cumprir, } \\
\text { benefícios, tudo parecido com o } \\
\text { trab. Formal }\end{array}$ & 9 & 8,5 \\
\hline Total & $106^{*}$ & 100,0 \\
\hline
\end{tabular}


Esse dado indica que existe um índice significativo dos que não se consideram como camelôs, o que ocorre pela "empresarização" que eles reconhecem em suas atividades, além da sofisticação dos produtos vendidos, diferentemente dos "camelôs tradicionais de rua” (Durães, 2013). Trata-se de um dado relevante, sobretudo, porque representa a percepção dos próprios trabalhadores que já se consideram empresários. Mesmo os camelôs situados como funcionários seguem essa ideia geral, apesar de dizerem que estão em um trabalho como outro qualquer. Além daqueles que se consideram como empresários, cerca de $40 \%$ ainda se considera como camelôs, o que mostra a complexidade desse tipo de trabalho: uma maioria se considerou empresário/empresa e quase metade se considera camelô.

Em comparação com a pesquisa realizada no Rio de Janeiro, observa-se uma presença maior daqueles que se consideravam camelôs (Durães, 2013). Esse percentual se reduz na pesquisa atual, já que cerca de $45 \%$ gostaria de mudar para um emprego com carteira assinada, enquanto $53,5 \%$ dos funcionários, e cerca de 30\% dos camelôs proprietários confirmam isto, mostrando um indicador diferente do que obtivemos no Rio de Janeiro, em que $65 \%$ queria mudar para um emprego com carteira assinada. Em relação aos benefícios dos funcionários, cerca de 33\% recebe além do salário, auxílio alimentação/transporte, férias e 13o salário. Mas cerca de 20\% recebe apenas o salário mínimo, enquanto cerca de $80 \%$ recebe algum tipo de benefício a mais, reunindo elementos que são bem característicos do universo formal, agora presentes nas ruas.

Grande parte dos entrevistados respondeu que se consideram independentes (83\%), tanto proprietário quanto funcionário se consideram dessa forma, o que evidencia a característica da autonomia. Contudo, cabe registrar que quase $100 \%$ dos proprietários se consideram assim (ou 96\%), enquanto entre os funcionários a sensação de liberdade caiu para cerca de $75 \%$ - evidenciando que existe uma relação dicotômica interna (ver tabela 10 abaixo).

Tabela 10 - Ser dono do negócio $\mathrm{x}$ autonomia no trabalho

\begin{tabular}{l|c|c|c|c}
\hline \multirow{2}{*}{} & \multicolumn{3}{|c|}{ Autonomia? } & \multirow{2}{*}{ Total } \\
\cline { 2 - 4 } & $\operatorname{sim}$ & não & $\begin{array}{c}\text { não } \\
\text { respondeu }\end{array}$ & \\
\hline Proprietário & $\begin{array}{c}52 \\
\text { Ou } 96 \%\end{array}$ & 2 & 0 & $\begin{array}{c}54 \\
\text { Ou } 100 \%\end{array}$ \\
\hline Funcionário & $\begin{array}{c}73 \\
0 u\end{array}$ & $22 \%$ & 2 & $\begin{array}{c}97 \\
\text { Ou } 100 \%\end{array}$ \\
\hline Total & 125 & 24 & 2 & 151 \\
\hline
\end{tabular}

Fonte: Pesquisa direta, 2015.

Como se sabe, a ideia da liberdade no trabalho sempre foi uma característica do informal, usada como justificativa para a permanência nesse tipo de trabalho e, em alguns casos, motivo para longas jornadas de trabalho e condições precárias, pois, estariam trabalhando para si (conta própria). Trata-se de um discurso presente nas formas de trabalho de rua no Brasil mas no caso em tela, termina reforçando a ideia de que são empresários, pois, um dos elementos representativos de ser proprietário é não ter patrão, logo, não estão, quando donos, submetidos a um controle direto sobre seu trabalho.

\section{O trabalhador de reserva e gratuito para o Capital}

O movimento incessante do capitalismo se dá em prol do aumento de produtividade, do "[...] interminável processo de obter lucros" (Marx, 2002, p.183-184), passando pelo crivo da formação de uma população apta para o trabalho, na condição de excedente. De acordo com Marx: "Quanto maiores a riqueza social, o capital em formação e [..] a magnitude absoluta do proletariado e da força produtiva de seu trabalho, tanto maior o exército industrial de reserva." (Marx, 2002, p.748). A população trabalhadora, portanto, ao produzir a acumulação do capital, produz, em proporções crescentes, os meios que fazem dela relativamente uma população supérflua/excedente (Marx, 2002, p.734).

Assim, para Marx 
[...] se uma população trabalhadora excedente é produto necessário da acumulação ou do desenvolvimento da riqueza no sistema capitalista, ela se torna, por sua vez, a alavanca da acumulação capitalista e, mesmo, condição de existência do modo de produção capitalista. Ela constitui um exército industrial de reserva disponível, que pertence ao capital de maneira tão absoluta como se fosse criado e mantido por ele. Ela proporciona o material humano a serviço das necessidades variáveis de expansão do capital e sempre pronto para ser explorada [...]. (Marx, 2002, p.735).

Portanto, o movimento de acumulação do capital, conforme Marx, gera inevitavelmente uma população de trabalhadores excedentes que em sua maioria está apta para ingressar no mercado formal de trabalho. Forma-se assim uma "superpopulação relativa" a qual pode ser caracterizada como sendo constituída por todos os trabalhadores que estão desempregados ou parcialmente empregados (Marx, 2002, p.741). A superpopulação relativa assume três formas: flutuante, composta por trabalhadores que perderam seus postos com o próprio crescimento da economia; latente, geralmente composta pelos trabalhadores rurais, que estão rebaixados da linha do pauperismo; estagnada, formada por parte dos trabalhadores em ação, mas que estão inseridos em ocupações totalmente irregulares. E é esta (última) forma que vai ser a mais relacionada à informalidade, aos trabalhadores de rua, pois uma parte da população flutuante que perde postos de trabalho no mundo formal termina จิ se encaixando nas redes de sobrevivência da formais, como tínhamos dito antes.

Nessa perspectiva, os trabalhadores de rua têm uma dupla funcionalidade: 1) pressio$\therefore$ nam os trabalhadores formais a permanecerem ले em seus empregos; 2) servem para baratear o

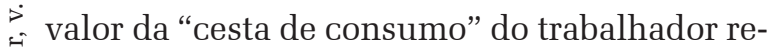
gular, logo estagnar seu salário, por venderem produtos a preços mais baixos do que em lojas formalizadas. O trabalho de rua também está submetido ao domínio do capital, fazendo parte do processo de circulação das mercadorias, ou seja, transforma o "capital-mercadoria" em dinheiro, o qual irá para a mão do comerciante, o qual o utiliza para comprar novas mercadorias e, assim, novamente, volta à mão do produtor, para se tornar "capital-dinheiro" e reiniciar o ciclo (Marx, 1991). Esse mecanismo da produção necessita da esfera da circulação, que envolve custos (transporte dos produtos, armazenamento e distribuição das mercadorias) (Marx, 1991). Tudo isso é feito "gratuitamente" pelo trabalhador de rua, sem custos para o capital, o que caracteriza o trabalhador gratuito para o capital (Durães, 2005, p.233).

Esse trabalhador também está sujeito a duas ordens de fatores: (1) ao próprio fluxo do capital, o qual, por exemplo, em momentos de aumento do custo da mercadoria, condiciona-o a endividar-se para continuar adquirindo a mercadoria (que subiu de preço) e manter-se na atividade; (2) ao próprio fluxo da atividade, que expõe o trabalhador à propensão a aumentar o desgaste e o "custo" de sua auto-reprodução, devido às condições precárias do trabalho na rua - longas jornadas, baixos rendimentos, inferências climáticas, violência urbana, fiscalização e controle do espaço público por parte do poder municipal - contribuindo para aumentar a vulnerabilidade à Saúde.

Ademais, este trabalhador tende a assumir valores instituídos, que muitas vezes se distanciam de suas condições de vida e, ainda assim, são vivenciados. Com isso, geralmente, constituem e lutam para manutenção de um status forçado, pois se privam de determinadas necessidades imediatas (alimentação, saúde...) para atenderem a essa vontade imputada, reflexo dos valores capitalistas do mundo corrente: consumismo e individualismo. Harvey (1999) exemplifica essa intensificação na construção de imagens de mundo como um mecanismo de manipulação de desejos. No entanto, de acordo com Prandi (1978), o trabalho informal contribui para evitar o conflito de classes, o que ocorre devido à aparência de autonomia no trabalho que oculta a relação capital e trabalho que se encontra numa forma disfarçada de assalariamento. O que acarreta as condições de inserção 
no processo de acumulação é o próprio movimento do capital que cria determinadas possibilidades de produção, de reprodução. E como salienta Prandi, o capital as mantém informais.

\section{CONCLUSÃO}

A informalidade de rua apresenta-se de um novo modo, deixando de ser apenas um espaço de sobrevivência dos camelôs tradicionais, cujo perfil correspondia a pouca escolaridade, baixa qualificação e baixa renda. Torna-se um espaço de obtenção de maiores rendas, sendo composto por influências do capitalismo e incorpora traços dos trabalhos formais, seja no que se refere às novas relações de assalariamento; seja nos usos de instrumentos, como cartões de visita, adoção de pagamento via cartões de crédito e débito; garantia, além de serem compostos por pessoas com maior qualificação e escolaridade. Contudo, apesar dessa nova roupagem, o trabalho informal mantêm características singulares das atividades de rua, ligadas à criatividade. O que ocorre é uma incorporação da lógica do trabalho formal, pois, esses ainda atuam sem registro de microempresa, possuindo apenas uma inscrição na Prefeitura e o registro como MEI, que não garantem direitos sociais mais amplos.

Conclui-se, portanto, que ao analisar a informalidade deve-se envolver uma série de fatores onde se faz necessário pensar a categoria informalidade dentro das relações e reproduções capitalistas ampliadas, permitindo compreender o informal no universo da globalização. A ligação da informalidade com o capitalismo permite colocar essas atividades no mesmo nível que qualquer forma de trabalho, pois a própria dinâmica do sistema criou e usa dessa informalidade (para valorização, produção e circulação de riquezas), por esse motivo esta não poderia representar espaços de autonomia simplesmente, mesmo porque esse tipo de trabalho informal possui elementos similares aos do trabalho formal.
Agora fica visível lógicas parecidas de trabalho e de lucro, onde tem-se o ganho, através da exploração do trabalho e à dinâmica da acumulação via circulação de mercadorias sem custos para o grande capital dos produtos tecnológicos. Isso se torna notório quando nos remetemos ao grande número de funcionários no camelódromo, ${ }^{16}$ que constitui um processo de exploração do trabalho e de produção de riqueza através do valor-trabalho, ou quando observamos a discrepância na relação de renda entre funcionários e proprietários, vemos a própria lógica capitalista em processo. A informalidade, dessa forma, acaba por ser uma modalidade de expansão capitalista no comércio de mercadorias globais em diversas cidades do mundo e que deve ser entendida com suas contradições e potencialidades constitutivas.

Ficou evidente que esse trabalhador em Feira de Santana que tratamos como camelôs (tanto proprietários quanto funcionários), que possuem agora uma identificação como empresários, representa um fenômeno contraditório. Eles ocupam o espaço da rua, são regulados pelo poder público municipal e possuem a marca da instabilidade de permanência no local de trabalho e incerteza de ganho financeiro futuro, mas conseguem subcontratar e terem maiores ganhos. Ou seja, são sim trabalhadores, mas agora com um perfil de negócio com conexão direta com a sociedade do capital através dos produtos vendidos e pela lógica de trabalho precária e de estilo inovador.

Data de recebimento 24 de setembro de 2018 Data de aceitação01 de outubro de 2020

\section{REFERÊNCIAS}

ABÍLIO, Ludmila Costhek et. al. Condições de trabalho de entregadores via plataforma digital durante a Covid -19. Revista Jurídica Trabalho e Desenvolvimento Humano. (DOSSIE COVID-19). p. 1-21, https://doi.org/10.33239/ rtdh.v1i1, 2020.

ABÍLIO, Ludmila Costhek. Uberização traz ao debate

${ }^{16}$ Estimamos em 700 funcionários no camelódromo, conforme conversas diretas no local no período da pesquisa. 
a relação entre precarização do trabalho e tecnologia. Revista do Instituto Humanitas Unisinos - IHU on-line. $\mathrm{n}^{\mathrm{o}}$ 503, Ano XVII, p. 20-27, 2017.

ABÍLIO, Ludmila Costhek. Uberização: uma era do trabalhador na hora certa? Estud. av. , São Paulo, v. 34, n. 98, p. 111-126, abril de 2020. Disponível em <http:// www.scielo.br/scielo.php?script $=$ sci_arttext\&pid $=$ S010320000100111\&lng $=$ en\&nrm $=$ iso $>$. $\quad$ https://doi. org/10.1590/s0103-4014.2020.3498.008, 2020. Acesso em 28.06.2020.

ALIANÇA BIKE. Pesquisa de perfil de entregadores ciclistas de aplicativo. Disponível em: http://aliancabike. org.br/pesquisa-de-perfil-dos-entregadores-ciclistas-deaplicativo/. São Paulo: Aliança Bike, 2019. Acesso em 27.06 .2020 .

ANTUNES, Ricardo. Os sentidos do trabalho: Ensaio sobre a afirmação e a negação do trabalho. 2 Ed. São Paulo: Boitempo Editorial, 2000.

ANTUNES, Ricardo. O Caracol e sua Concha: ensaios sobre a nova morfologia do trabalho. São Paulo: Boitempo, 2005.

ANTUNES, Ricardo. O privilégio da servidão: o novo proletariado de serviços na era digital. São Paulo: Boitempo, 2018.

ANTUNES, Ricardo. [E-boook]. Coronavírus: o trabalho sob o fogo cruzado. São Paulo: Boitempo, 2020.

BAUWENS, T.; LEMAÎTRE, A. Popular Economy in Santiago de Chile: State of Affairs and Challenges. World Development, 64: 65-78. Disponível em: https://doi. org/10.1016/j.worlddev.2014.05.015, 2014. Acesso em: 11.09. 2020.

BANKS, Nicola; LOMBARD, Melanie; MITLIN, Diana. Urban Informality as a Site of Critical Analysis. The Journal of Development Studies, 56: 2, 223-238. Disponível em: https://doi.org/10.1080/00220388.2019.1577384, 2020. Acesso em: 11.09.2020.

BOUDAUD, V. What does Uberization mean? 2015. Disponível em: https://www.linkedin.com/pulse/what-doesuberization-mean-vero-boudaud. Acesso em: 19.12.2017.

BELLUZZO, L. G. Informalidade formalizada. Site Instituto Humanitas Unisinos. Disponível em: http://www.ihu. unisinos.br/602702-informalidade-formalizada-artigo-de-luizgonzaga-belluzzo, 2020. Acesso em 11 de setembro de 2020.

BRASIL. Lei Federal 13467/2017 (Altera a Consolidação das Leis do Trabalho) [Reforma Trabalhista]. Governo Federal. Brasília: DF, 13 de julho de 2017.

BROMLEY, R.; WILSON, T. Introduction: the urban informal economy revisited. Latin American Perspectives, 45 (218):4-23.

D Disponível em: https://doi.org/10.1177/0094582X17736043, กิ 2018. Acesso em: 11.09. 2020.

๗ CACCIAMALI, M. C. Globalização e processo de กิ informalidade. In: Economia e Sociedade, Campinas: 오 Unicamp. I.E., n. 14, p.152-174, jun. 2000.

CANCLINI, N. G. A culture of informality. Urban ‡゙ Studies, 56(3), 488-493. Disponível em: https://doi. I org $10.1177 / 0042098018782635,2019$. Acesso em: 11.09.2020.

2. CARNEY, B. M. Let's Uberize The Entire Economy, ळ 2014. Disponível em: https://www.forbes.com/

$\Longrightarrow$ sites/realspin/2014/10/27/lets-uberize-the-entirei economy/\#79211def4c60. Acesso em: 07.02.2016.

CAMPOS, A. G (Org.). A terceirização do trabalho no Brasil: $\geq$ novas e distintas perspectivas para o debate. Brasília: ऽ Ipea, p. 113-141. 2018. Disponível em: Http://www.ipea. تi gov.br/portal/images/stories/PDFs/livros/livros/180215 terceirizacao do trabalho no brasil novas e distintas perspectivas_parā_o_debatē.pdf. Acessso em: $\overline{1} 3$-03.03.2018.

CAMPOS, F. Meca da pirataria: Feiraguai cresce em ritmo chinês e é a terceira do país em contrabando. In: Correio da Bahia. Salvador. https://www.correio24horas.com.br/ noticia/nid/meca-da-pirataria-feiraguai-cresce-em-ritmochines-e-e-a-terceira-do-pais-em-contrabando, 2013. Acesso em 11 de setembro de 2020.

CHEN, M. (2012). The informal economy: definitions, theories and policies. USA: WIEGO Working Paper, n. 1. Disponível em: https://www.wiego.org/sites/default/files/ publications/files/Chen_WIEGO_WP1.pdf, 2012. Acesso em: 11.09.2020.

DRUCK, M. G. Precarização social do trabalho. In: IVO, A. et al. (Orgs.). Dicionário temático desenvolvimento e questão social: 81 problemáticas contemporâneas. Rio de Janeiro: Annablume, 2013, v. 1, p. 373-381.

DRUCK, G. et. al. A terceirização no serviço público: particularidades e implicações. In.: CAMPOS, A. G (Org.). A terceirização do trabalho no Brasil: novas e distintas perspectivas para o debate. Brasília: Ipea, p. 113-141. 2018. Disponível em: Http://www.ipea.gov.br/portal/ images/stories/PDFs/livros/livros/180215_terceirizacao_ do trabalho no brasil novas e distintas perspectivas para_o_debāe.pdf. Acesso em: $\overline{1} \overline{3} .03 .2018$.

DRUCK, G; JESUS, S. C. S.; DUTRA, R. Q. A contrarreforma neoliberal e a terceirização: a precarização como regra. Cadernos CRH, v. 32, p. 289-305, 2019.

DURÃES, Bruno J. R. Trabalho de rua em Salvador e sua contribuição para acumulação capitalista: o trabalhador gratuito. In: Temáticas, ano 13, n. ${ }^{\circ}$ 25/26, IFCH/UNICAMP, p. 217-238, 2005.

DURÃES, Bruno J. R. Trabalhadores de rua de Salvador: Precários nos cantos do século XIX para os encantos e desencantos do século XXI. 237p. Dissertação. (Mestrado em Sociologia) - Programa de Pós-graduação em Sociologia da Universidade Estadual de Campinas, 2006.

DURÃES, Bruno J. R. Trabalho de rua, perseguições e resistências: Salvador no final do século XIX. In: Revista Brasileira de História \& Ciências Sociais, RBHCS, v. 4, n. 7, p.72-93, 2012.72

DURÃES, Bruno J. R. Camelôs globais ou de tecnologia: novos proletários da acumulação. Salvador: Edufba, 2013.

DE STEFANO, V. The rise of the "just-in-time workforce": On-demand work, crowdwork and labour protection in the "gig-economy". Conditions of Work and Employment Series, Geneva, n.71, 2016.

FERNANDES, F. A Revolução Burguesa no Brasil: ensaio de interpretação sociológica. 2.ed. Rio de Janeiro: Zahar Editores, 1976.

FILGUEIRAS, Luiz A. M.; DRUCK, G.; AMARAL, M. $O$ conceito de informalidade: problema ou solução? Salvador: Faculdade de Ciências Econômicas, 2000 (mimeo).

GAMA, Stefano H. Garimpeiros urbanos, a valorização do "lixo" e a desvalorização do trabalho: um estudo de caso com catadores de materiais recicláveis de Salvador. 2015. 190p. Dissertação (Mestrado em Ciências Sociais) - Programa de Pós-graduação em Ciências Sociais da Universidade Federal da Bahia.

GIMENEZ, Denis M.; KREIN, J. D. Terceirização e o desorganizado mercado de trabalho brasileiro. In: TEIXEIRA, M.; ANDRADE, H. R.; COELHO, E. (Orgs.) Precarização e terceirização: faces da mesma moeda. São Paulo: Sindicato dos Químicos, p.17-33, 2016.

GODINHO, Luis Flávio R. Laços Frágeis, identidades fragmentadas: Interações, discriminações e conflitos entre trabalhadores da Refinaria Landulfo Alves - Mataripe. Bahia - 1990-2006. 250p. Tese. (Doutorado em Sociologia). Programa de Pós-graduação em Sociologia da Universidade Federal da Paraíba, 2008.

GROHMANN, R. Plataformização do trabalho: entre a datificação, a financeirização e a racionalidade neoliberal. Revista Eptic., v.22, n.1, p.106-22, 2020. 
HARVEY, David. A condição pós-moderna. Tradução de Adail Sobral; Maria Gonçalves. 8. ed. São Paulo: Edições Loyola, 1999

HARVEY, David. O Novo Imperialismo. 2. ed. São Paulo: Loyola, 2005.

HARVEY, David. Política anticapitalista em tempos de Covid-19. In: Coronavírus e a luta de classes. Brasil: Editora Terra Sem Amos, p. 13-24, 2020.

HILL, S. The Future of Work in the Uber Economy, 2015. Disponível em: <http://bostonreview.net/us/steven-hilluber-economy-individual-security-accounts $>$. Acesso em: 19 de dezembro de 2017.

IBGE. Feira de Santana. Cidades. IBGE. Disponível em https://cidades.ibge.gov.br/brasil/ba/feira-de-santana/ panorama, 2020. Acesso em 11 de setembro de 2020.

ILO. Measuring informality: a statistical manual on the informal sector and informal employment. Geneva: ILO Publications, 2013.

ILO. Informality and non-standard forms of employment. Buenos Aires: Ilo, 2018.

ILO. Contagion or starvation, the dilemma facing informal workers during the COVID-19 pandemic. 2020. Disponível em: https://www.ilo.org/global/ about-the-ilo/newsroom/ news/WCMS 744005/lang--en/index.htm, 2020. Acesso em 11 de setēmbro de 2020.

LAUTIER, Bruno. L'économie informelle dans Le tiers monde. $2^{\text {a }}$ E.d. Paris: Éditions La Découverte, 2004.

LIMA, Ângela M. de S. As faces da subcontratação do trabalho: um estudo com trabalhadoras e trabalhadores da confecção de roupas de Cianorte e região. 353p. Tese. (Doutorado em Ciências Sociais). Programa de Pósgraduação em Ciências Sociais, 2009.

LIMA, Jacob Carlos; SOARES, Maria José. Trabalho Flexível e Novo Informal. In: Caderno do CRH, Salvador, Ufba, n.37, p.163-180, 2002.

MACHADO DA SILVA, Luis Antônio. Da informalidade à empregabilidade. Reorganizando a dominação no mundo do trabalho. In: Caderno do CRH, Salvador, Ufba, n.37, p.81-109, 2002.

MAIA, Renata. Ministério Público pede realocação do 'Feiraguay', maior centro de compras populares de Feira de Santana, na Bahia. G1 notícias/TV Subaé. 2019. Disponível em: https:/g1.globo.com/ba/bahia/noticia/2019/09/25/ ministerio-publico-pede-realocacao-do-feiraguai-maiorcentro-de-compras-popularres-de-feira-de-santana-nabahia.ghtml . Acesso em 14 de setembro de 2020.

MARX, K. O Capital Comercial. In:

Capital: $\mathrm{O}$ Processo Global de Produção Capitalista. Tradução de Reginaldo Sant'Anna. 5 $5^{\mathrm{a}}$ Ed. Rio de Janeiro: Editora Bertrand Brasil, 1991. Cap. XVI do Livro 3, v. 5, p. 309-323.

O capital: crítica da economia política: Livro v. 1 e 2. Rio de Janeiro: Civilização Brasileira. Tradução de Reginaldo Sant'Anna, 2002.

MÉSZÁROS, Istvan. Para Além do Capital. Tradução de Paulo César Castanheira e Sérgio Lessa. São Paulo: Boitempo Editorial; São Paulo: Editora da Unicamp, 2002.

MOSCA, J. Pobreza, Economia “Informal”, Informalidades e Desenvolvimento. In BRITO, L.D.; CASTEL-BRANCO, C. N.; FRANCISCO, S. C. Pobreza, Desigualdade e Vulnerabilidade em Moçambique (p. 83-95). Maputo: Instituto de Estudos Sociais e Económicos, 2010.

NOVAIS, Fernando. Portugal e Brasil na crise do Antigo Sistema Colonial (1777 1808). 6. ed. São Paulo: Hucitec, 1995.

OLIVEIRA, Patrícia M. de. Formação e legalização do feiraguai: Uma questão discursiva. 2013. 95p. Dissertação. (Mestrado em Letras). Programa de Pós-graduação em estudo de linguagens da Universidade do Estado da Bahia (Uneb).
PRADO JÚNIOR, Caio. História Econômica do Brasil. 41. ed. São Paulo: Brasiliense, 1994.

PRANDI, José Reginaldo. O trabalhador por conta própria sob o Capital. São Paulo: Edições Símbolo, 1978.

REIS, João José. A Greve Negra de 1857 na Bahia. In: Revista da USP, São Paulo, n. 18, p.6-29, jul. ago. 1991.

REIS, João José. De olho no canto: trabalho de rua na Bahia na véspera da Abolição. In: Afro-Ásia. Salvador, 24, p. 199242,2000

REIS, João José. Ganhadores: a greve negra de 1857 na Bahia. São Paulo: Companhia das Letras, 2019.

SANTANA, M. A.; DRUCK, M. G. Terceirização e degradação do trabalho nas universidades brasileiras. Margem Esquerda, v. 25, p. 52-57, 2015.

SANTOS, Claudio R. dos. Shopping popular Feiraguai: estudos sobre a produção de um espaço de comércio em Feira de Santana - BA. Tese de Doutorado. Rio Claro: Universidade Estadual Paulista/UNESP. Instituto de Geociências e Ciências Exatas, 2016

SCHOR, Juliet. "Debating the sharing economy". In Great Transition Initiative, out. 2014. Disponível em: https:// greattransition.org/publication/debating-the-sharingeconomy. Acesso em: 12.09.2018.

SCHOLZ, Trebor. Cooperativismo de plataforma: contestando a economia do compartilhamento corporativa: Trebor Scholz Título original: Platform Cooperativism: Challenging the Corporate Sharing Economy Tradução e comentários: Rafael A. F. Zanatta São Paulo: Fundação Rosa Luxemburgo; Editora Elefante; Autonomia Literária, 2016

SENNETT, Richard. A corrosão do caráter: conseqüências pessoais do trabalho no novo capitalismo. Traducão de Marcos Santarita. Rio de Janeiro e São Paulo: Editora Record, 2000

SILVA, Omarildo Luís da. O impacto da economia informal no processo de desenvolvimento na Africa Subsariana. Dissertação de Mestrado. Universidade Técnica de Lisboa. Instituto Superior de Economia e Gestão, 2010.

SLEE, Tom. Uberização: A nova onda do trabalho precarizado. São Paulo: Editora Elefante, 2017, 320p.

SOUZA, E. A “maquiagem” do trabalho formal: um estudo do trabalho das mulheres terceirizadas no setor de limpeza na Universidade Federal da Bahia. 2012. Dissertação (Mestrado) - Faculdade de Filosofia de Ciências Humanas, Universidade Federal da Bahia, Salvador, 2012

SRNICEK, Nick. Platform capitalism. Cambridge, UK; Malden, MA: Polity Press, 2016.

TAVARES, Maria Augusta. Os fios (in)visíveis da produção capitalista: informalidade e precarização do trabalho. São Paulo: Cortez, 2004.

TELES, Alessandra O. O comércio informal em Feira de Santana (BA): Permanências e mudanças. Tese (Doutorado em Geografia) - Programa de Pós-Graduação em Geografia da Universidade Federal de Sergipe. São Cristóvão, 2017.

VASAPOLLO, Luciano. O trabalho atípico e a precariedade. Tradução Maria de Jesús Brito Leite. São Paulo: Expressão Popular, 2005.

WILLIAM, C.; SHAHID, M.; MARTÍNEZ, Á. determinants of the level of informality of informal micro-enterprises: some evidence from the city of Lahore, Pakistan. World Development, 84: 312-325. Disponível em: https://doi. org/10.1016/j.worlddev.2015.09.003, 2016. Acesso em 11 de setembro de 2020.

ZUBOFF, S. Big other: capitalismo de vigilância e perspectivas para uma civilização de informação. In: BRUNO, F. et al. (Org.) Tecnopolíticas da vigilância: Perspectivas da margem. São Paulo: Boitempo, 2018. 


\section{THE RECONFIGURED PEDDLER: Your function for accumulation}

\section{Bruno José Rodrigues Durães}

This paper deals with street workers that offer technological products (cell, games, flash drivers etc.) in Camelódromo Feiraguai in Feira de Santana. It was intended to answer the following question: Is the peddler of a differentiated form of technology for informal street work, which is the predominant business (profit), business (the capital) and not the employee (linked to survival)? this line will be activities that now serve as the veins of capital expansion? Our aim of this research: to explore the new forms of differentiation in this street work in the current Brazilian society, ie, understand what is this new (re) configuration of the street. This phenomenon reflects a kind of activity that suffers direct interference of the formal world, reshaping itself and assuming business features. 151 questionnaires were applied to these vendors. It was found that is a style of work and business logic, but still within the framework of informal work.

KeYwords: Informality. Peddler of technology. Capitalism.

\section{TRAVAIL INFORMEL DE RUE RECONFIGURÉ: son rôle d'agent d'accumulation}

\author{
Bruno José Rodrigues Durães
}

Cet article traite des travailleurs de rue qui offrent des produits technologiques (cellulaire, jeux, pilotes flash, etc.) dans le Camelódromo Feiraguai à Feira de Santana - Bahia. Il avait pour but de répondre à la question suivante: La technologie est colporteur une autre forme de relation informelle de travail de rue, où la logique prédominante est l'entreprise (profit) de la société et non l'employé (sur la survie)? Dans cette ligne, ces activités serviront-elles maintenant de filons d'expansion du capital? Nous avions l'objectif général de cette recherche: pour explorer cette nouvelle différenciation dans cette forme de travail de rue dans la société brésilienne actuelle, à savoir comprendre ce que cette nouvelle (re) configuration de la rue. Ce phénomène montre un type d'activité qui subit une interférence directe du monde formel, se reconfigurant et assumant des fonctions commerciales. 151 questionnaires ont été appliqués à ces vendeurs de rue. On a constaté que est un style de travail et la logique formel, mais toujours dans le style du travail informel.

Mots-CLÉs: Informalité. Camelot de la technologie. Le capitalisme. Ciências Sociais pela Unicamp, professor de Sociologia e da Pós-Graduação em Serviço Social (Política Social e Territórios/POSTERR) da UFRB, pesquisador do CRH/UFBA, membro da Comissão de Ética da direção nacional da Associação Brasileira de Ensino de Ciências Sociais (ABECS) e ex-Coordenador do Curso de Licenciatura em Ciências Sociais da UFRB. Autor do Livro: "Camelôs globais ou de tecnologia: novos proletários da acumulação" pela Edufba (2013). 